\title{
Exploring the Anthropology of Energy: Ethnography, Energy and Ethics
}

J essica Smith, Colorado School of Mines

Mette High, University of St. Andrews

The remarkable grouth in global energy consumption has been accompanied by increasingly urgent questions about which energy sources ought to fuel the spiraling demand. Witness the recent controversy surrounding the North Dakota Access Pipeline, for example, in which activists joined forces with Native American groups in an attempt to halt the final phase of construction. News of the protests reached around the world, raising concern not just about Native American sovereignty and potential water and ground pollution of the transported oil, but also about the pipeline's facilitation of our more general continued reliance on fossil fuels that hasten climate change. Supporters of the pipeline pointed out that pipelines are safer than railroads for transporting the oil on which the US currently depends, and argued that the pipeline would bring economic benefits in the form of jobs and increased energy availability. The pipeline project thus became a flashpoint for much larger debates about the kinds of energy futures that people desire and how these impact the everyday lives of people along the paths of production, distribution, consumption, and waste.

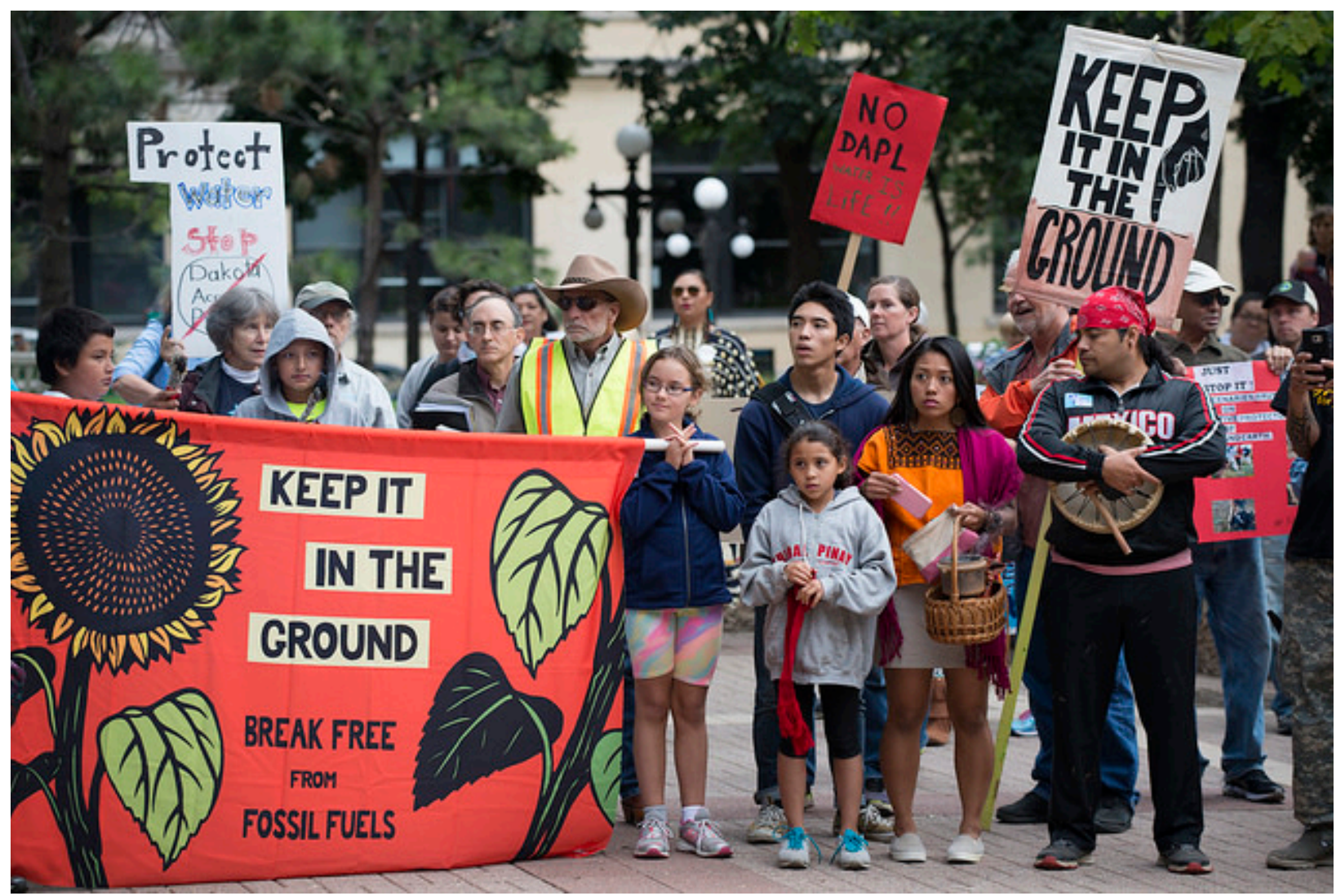

Figure 1: Rally against the Dakota Access Pipeline in St. Paul, Minnesota. Licensed under a Creative Commons Attribution License. Original source: Fibonacci Blue. 


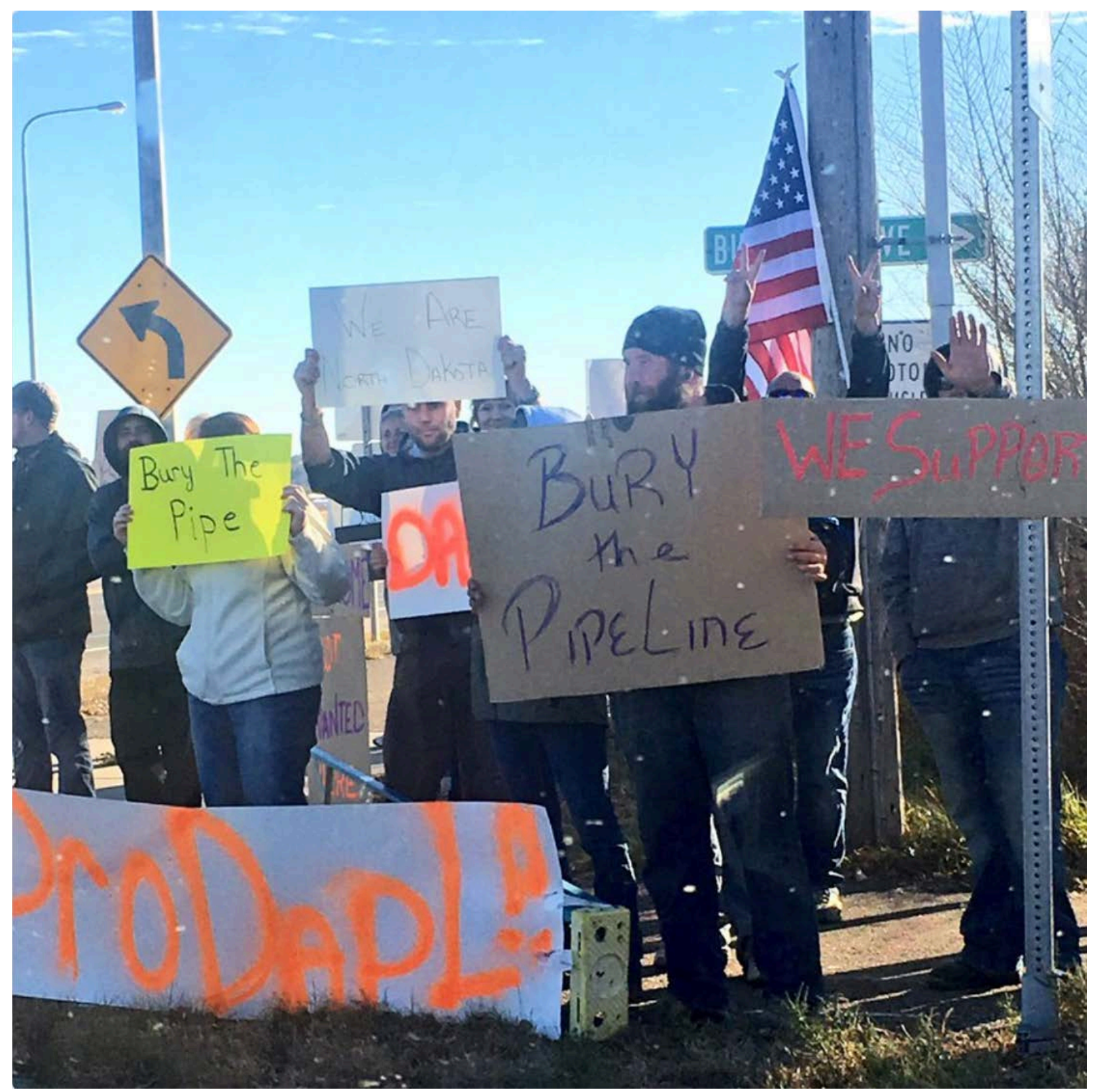

Figure 2: Pro Dakota Access Pipeline demonstrators in North Dakota. Photo credit Dena Takruri @Dena.

This Special Issue shows that debates about energy raise fundamental ethical questions that involve judgments about the kinds of lives we desire for ourselves and our others: What is the place of energy in human life? How do we make sense of the ways in which we produce, distribute, use and dispose of it? And how do such actions relate to what we consider to be right or good? The articles highlight the unique contributions an ethnographic perspective offers to understanding how people themselves encounter energy and judge its place in their lives. Towards this end, we propose the term energy ethics to capture the ways in which people understand and ethically evaluate energy: how do people judge the ways in which energy can contribute to or imperil the kinds of lives, societies, and futures that they deem to be good or valuable? We emphasize that our approach takes seriously people's own ethical sensibilities in relation to energy, working from the ground up, rather than analyzing social life through pre- 
defined notions of ethics. Energy ethics illuminates the multiple and varied ways that people experience, conceptualize, and evaluate matters of energy in their lives.

Our approach to energy ethics is distinct but complementary to the growing literature on energy justice. Scholars working in this area define energy justice as a "global energy system that fairly disseminates both the benefits and costs of energy services, and one that has representative and impartial energy decision-making" (Sovacool et al. 2016: 4; see also Sovacool and Dworkin, 2014; Sovacool 2013). The field is guided by ten principles: availability, affordability, due process, transparency and accountability, sustainability, intergenerational equity, intragenerational equity, responsibility, resistance and intersectionality (Sovacool et al. 2017). While these principles have been generative for inspiring research, policymaking and practice that seeks to make energy systems fairer in terms of these particular principles, they too are social constructions that emerge from particular historical and cultural contexts (Heffron and MoCauley 2017). The field is building on this insight, as evidenced by the call to include more non-western justice theorists (Sovacool et al. 2017) and research that identifies how actors themselves frame energy justice in their own activities (Fuller and McCauley 2016). It is an "evaluative and normative" approach in which "energy justice researchers both assess injustices and make recommendations on how they should be approached" (J enkins et al. 2016: 175).

In this Special Issue our focus on energy ethics takes a different approach. Rather than applying a preexisting framework to evaluate a particular context, we identify how people themselves judge the rightness and wrongness of energy. Starting from the ground up opens up analytic space to consider ethical sensibilities that inform how people understand and judge energy systems, but are not necessarily captured in the ten principles forming the basis of the energy justice literature.

Shedding light on the multiple energy ethics that emerge in culturally distinct places requires exploring how people understand energy. This task may initially seem straightforward, especially if "energy" is considered in abstract terms to be the fundamental ability to do work. Commonsense might even suggest that 'energy' accomplishes similar things for a variety of people irrespectively of their particular sociocultural, geographic or economic location; according to this logic, energy improves lives by allowing people transportation and mobility and opportunities to light homes, schools and businesses. Providing people access to these 'basic' or 'universal' energy needs animates many energy justice activities and global corporate advertisement campaigns. However, as this Special Issue demonstrates, once we begin to look more closely and consider the multiple and varied ways in which individual people encounter energy - and desire to encounter energy - the question of how they understand what energy actually is transforms into an invitation for transdisciplinary ethnographic scholarship. It becomes an opportunity to consider empirically how people live with energy and how energy may or may not contribute to their definition of a good life.

Admittedly ambitious in its scope, this Special Issue cuts across conventional analytical divisions that separate production, distribution, consumption and waste into distinct fields of inquiry. It also extends across wide-ranging geographical regions and, not least, it challenges scales that seek to isolate global concerns from local realities. Our authors come from a variety of disciplines, including American Studies, Sociocultural Anthropology, Forestry and Environmental Science, Literature, Philosophy, and Science and Technology Studies. This diversity reflects how ethnographic approaches to research have travelled across disciplines. Throughout, these diverse scholars show what qualitative methods, especially an ethnographic gaze, can bring to our understanding of energy expectations and practices. 
Out of the diversity of fieldsites, research methods, and conceptual frameworks, three clear themes emerge. The first is that multiple, conflicting understandings of energy animate how people engage it in their everyday lives and work. The second is that great diversity exists in how people make ethical judgments about the role of energy in the types of "good lives" and "good societies" they imagine for themselves. Each of the papers troubles a normative ethical framework of fairness, showing that there is no singular set of values that are shared equally at all times by all actors. ${ }^{1}$ Finally, the papers underscore the significance of government interests and public policy for shaping people's experiences of and ethical judgments about energy. These perspectives reveal the value of research that is attuned to the ways in which people view the world and the place of energy in it, opening up space to identify and reflect on our taken-forgranted assumptions.

\section{Why ethnography?}

The term ethnography has come to be equated very broadly with qualitative research projects that seek to provide a detailed, in-depth description of everyday life. This broad conceptualization is captured in the term's Greek etymology of cं $\theta$ vos ethnos 'folk, people,' and

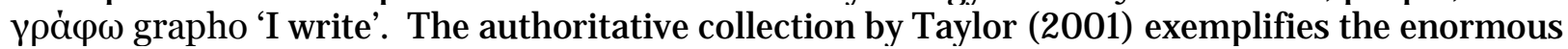
variety in ethnographic research, demonstrating various approaches to data gathering, data processing and project design. However, amidst the variety, some shared characteristics do appear. Whether it is a tightly scheduled research team or a single researcher engrossed in longterm data gathering, whether researchers draw on mostly discrete methods of formal data collection or open-ended informal interactions, ethnographic research, for Taylor, is characterized by its empirical approach. Through especially first-hand observation, ethnographers set out to study people and, what Taylor calls, their "social worlds" (2001:1)2. Based on their observation, they produce texts that aim to be "full, nuanced and non-reductive" (ibid.:2). Alongside such observation, Hammersley and Atkinson (2007) also emphasize the importance of first-hand participation. As they note:

Ethnography usually involves the researcher participating, overtly or covertly, in people's daily lives for an extended period of time, watching what happens, listening to what is said, and/ or asking questions through informal and formal interviews, collecting documents and artefacts - in fact, gathering whatever data are available to throw light on the issues that are the emerging focus of inquiry (Hammersley and Atkinson 2007:3).

Given ethnographers' broad range of data gathering activities, O'Reilly poignantly remarks how ethnography is not so much a method of data collection as it is "an approach to research" (2012:3). This approach is fluid and flexible, constantly adjusting to and reflecting on the data being gathered. Instead of starting with set hypotheses to test, ethnographic research often lays out a theoretical problem or question that guides the evolving design and process of the research. ${ }^{3}$ With no clear demarcations between data gathering and data processing, the research

\footnotetext{
${ }^{1}$ For an interesting debate in relation to climate ethics and the (im)possibility of a universal notion of 'justice', see Gardiner and Weisbach (2016).

2 Ethnographic scholars refer to this also as "the human condition" (Bernard 2011:2), "ways of life" (Denzin 1997:xi), "human experience" (Willis and Trondman 2000:5). ${ }^{3}$ It is a commonplace view of ethnographic research that it is devoid of hypotheses and its aim is merely to understand and describe phenomena (Agar 1986:12). However, as Gobo (2008) reminds us, hypotheses are central to our everyday practices of reasoning and are routinely used
} 
thus proceeds in "a manner which is informed but open to surprises" (ibid.:30). As such, the researcher engages in a continuing process of both induction and deduction, of theory building and theory testing (Bernard 2011, Ezzy 2013:14).

Perhaps it is this open-ended approach to research that allows ethnographic research to be complemented so successfully with a whole suite of methods. Some of these may be participant observation and semi-structured interviews, biographies and life histories. Others may be more formal methods such as questionnaires and surveys, focus groups and experiments. Depending on the specific discipline within which we work, the questions we ask about the human condition may differ quite substantially. In terms of energy research specifically, there is a crucial difference between those of us for whom "the first principle of inquiry is that reality is constructed uniquely by each person (the constructivist view) and those of us who start from the principle that external reality awaits our discovery through a series of increasingly good approximations to the truth (the positivist view)" (Bernard 2011:2). Recognizing our epistemological differences, however, the actual methods we apply for data gathering belong to all of us (Bernard 1994).

Taking this point seriously, this Special Issue seeks to showcase the broad range of insights and applications of ethnography in energy studies. The contributors come from sociocultural anthropology and beyond. In the articles, we ask very different questions and draw on very different methods. Yet we all share the same fundamental approach to research, which O'Reilly above defines as 'ethnographic'. Rather than limiting ethnography as suitable for only certain disciplines, thereby reproducing disciplinary silos of knowledge production, we demonstrate that ethnography can in general deepen our understanding of energy expectations and practices. Indeed, we contend that this would also be the case for research that is more quantitative. There is no inherent or necessary bifurcation between qualitative and quantitative approaches to research. As Bernard warns us, "never use the distinction between quantitative and qualitative as cover for talking about the difference between science and humanism. Lots of scientists do their work without numbers, and many scientists whose work is highly quantitative consider themselves humanists" (2011:21). In our view, ethnography has precisely the potential to facilitate dialogue among researchers of various disciplines, offering an approach that not only travels easily across academic divides but also brings into sharp focus the individual people and their practices that we seek to better understand.

When we apply an ethnographic gaze, social life emerges with all its implicit and explicit relations, untold rules of thumb and self-aware sensitivities, underlying assumptions and clear intuitions, shared world views and conflicts of interest. A plethora of habits, rules, norms and constraints appear. Seeking to understand this ethnographically involves an "important bridge between macro and micro perspectives" (O'Reilly 2012:7, see also Geertz 2000). Rather than constituting distinct scales where we can choose which one to examine, the macro and micro are "confounded in one another" (Comaroff and Comaroff 2003:149). The local and the global, here and elsewhere, now and then, the concrete and the virtual are inseparable. Importantly, this inseparability is not merely theoretical, conceptual or abstract but rather "an empirical conjuncture" that forms the reality we seek to understand (ibid.:151). An ethnographic interest in, say, a family's smart meter operations requires attention to the material and moral conditions that animate their usage, as well as the social and political environment that they

both consciously and unconsciously to make sense of the world around us. This means that whilst fixed or rigid hypotheses to apply, test, and adopt or discard are generally avoided in ethnographic research, "working hypotheses" and "guiding hypotheses" (2008:88) that remain flexible and explorative do not conflict with this research aim. 
spawn. Looking ethnographically at how people understand energy thus entails scholarly attention to these awkward scales that simultaneously escape, embrace, consume and construct the local. Ethnography thus challenges our preconceived ideas and offers to take us on a journey that might be full of surprises.

\section{How have anthropologists studied energy?}

Anthropologists have long studied energy, but only recently began to organize their work along these lines. Indeed, anthropologists have used studies of particular energy sources-ranging from coal and oil to nuclear and renewables - to contribute to wider disciplinary debates. For example, a substantial anthropological literature on oil plays a key role in critiquing the pervasive resource curse literature (Apter 2005; Behrends et al., 2011; Weszkalnys 2011) and in advancing scholarship on the interrelationships of states, corporations and the communities closest to production sites (e.g. Appel 2012; Coronil 1997; Rogers 2015; Sawyer 2004). Anthropological research on oil has also made crucial interventions into theories of resources and resource materialities (Richardson and Weszkalnys 2014), highlighting the distributed networks of material technologies and infrastructures and regimes of expertise and representation that emerge along the points of extraction, production, marketing and consumption (Appel et al. 2015). Considering other energy sources, anthropologists examine the labor and environmental politics of coal mining (McNeil 2011; Rolston 2013, 2014) and offer a critical lens on renewable energy (Acheson and Acheson 2016; Campbell et al. 2016; Cross 2013; Gunel 2016; Howe and Boyer 2016; Howe 2014, 2017; Lord 2016; Love and Garwood 2013; Morris 2013). Anthropologists also point to the mutual imbrication of nuclear energy with the nuclear weapons complex (Brooks 2012; Gusterson 1998; Maasco 2008; Nader 1980).

Anthropological scholarship on energy more generally, rather than particular energy sources, historically appears in conjunction with heightened public and policy concern during energy crises and perceived energy transitions, including our current predicament. These stretch back to Leslie White's (1943, 1959) early evolutionary theory linking the "cultural development" of societies to their energy production, which was framed by his concerns about the implications of dwindling reserves of coal and oil and increasing world demand for energy. ${ }^{4}$ In the wake of the 1970s energy crisis, Laura Nader $(1980,1981)$ used her observations of nuclear scientists to call for more divergent thinking about the taken-for-granted values that inform scientific and policy debates about energy futures, spurring increased anthropological attention to experts and expertise. Other anthropologists documented troubling sociocultural and environmental impacts of energy development, especially for vulnerable communities and indigenous peoples (e.g. J orgensen et al. 1978; Kruse et al. 1982). After almost two decades of scarce anthropological research on energy, a revitalization of the field occurred in the early 2000s, sparked by multiple sources: renewed concerns about geopolitical uncertainty wrought by the Iraq War, the US onshore oil and gas production boom spurred by the twinned technologies of horizontal drilling and hydraulic fracturing, as well as climate change initiatives.

The edited book Cultures of Energy: Power, Practices, Technologies (Strauss et al., 2013) stands out as the first collection of anthropological studies of energy that together assert that "human use of energy is understood and experienced through cultural frameworks" (ibid.:11). Following this publication, special issues of anthropological journals have explored energy and

4See Boyer (2014), Mitcham and Rolston (2013), Strauss et al. (2013) for more detailed critiques of White's legacy for the anthropology of energy as well as the historical patterns in anthropological research on energy. 
political power (Boyer 2014), electricity's influence on anthropological theory and the human sciences (Boyer 2015), and energy and economy (Love and Isenhour 2016). Anthropologists also play a key role in the emerging field of the energy humanities (e.g. Szeman and Boyer 2017). This current generation of energy studies continues in the earlier vein by exploring how energy production and use unevenly distribute other forms of social, political and economic power. These studies stand out from previous approaches for their attention to patterns of consumption as well as production, and to renewable as well as fossil resources. For example, Cymene Howe and Dominic Boyer illustrate how the (now stalled) development of a massive wind park in Oaxaca, Mexico, inspired local resistance from nearby indigenous communities and fishers concerned about local environmental damage as well as disrespect of communal property regimes (Howe 2014) and how national electricity grids encourage demand and create subjects of the state (Boyer 2015).

This special issue's focus on ethnography, energy and ethics builds on and complements two key conceptual frameworks developed by anthropologists to study energy: energyscape and energopower. The authors of the Cultures of Energy volume propose the term energyscape, drawing on the anthropologist Arjun Appadurai's (1990) influential theoretical framework that draws attention to dynamic flows across boundaries of global economies, cultures and politics. Analyzing an energyscape allows the authors to shift across local, national, and transnational scales in order to "consider the problem of energy in motion across social and physical spaces, shifting its cultural, social, economic, and technological values as it flows from one domain to the next" (Strauss et al. 2013: 12). They offer a series of energy-inspired metaphors to conceptually link the chapters. Currents and flows, for example, are advanced to shed light on the "parallel between physical flows of energy and the circulation of social, economic, and political relationships that emerge in the context of energy systems" (ibid.:12), while transformation draws attention to social change and transitions (12). In a special issue of Anthropological Quarterly, Dominic Boyer offers the analytic frame of energopower to focus scholarly attention to the interrelations of energy and political power identified by many anthropologists, including those in the Cultures of Energy volume. ${ }^{5}$ As a "genealogy of modern power that rethinks political power through the twin analytics of electricity and fuel" (2014: 325), energopower has the potential to draw together otherwise disparate research into a shared scholarly discussion.

The authors of this Special Issue engage both approaches to studying energy. As a whole, our collection illustrates how energy and energy infrastructure take on different values in different locations. Disagreement about energy production from coal seam gas development threatens a community in Australia (Grubert and Skinner), whereas a New Mexican town negotiates becoming the only nuclear waste storage facility in the US (Richter). Residents of two Zambian copper mining towns desire more access to the electricity that flows to the mines (Kesselring), whereas transmission lines in the US can be viewed as an unwelcome visual blight (Wuebben). The study of 'energy biographies' even shows how energy consumption can take on different valences for the same person (Groves). The articles also draw on the notion of energopower to show how political power is exercised through energy infrastructure, from the labs of synthetic biologists (McLeod) to off-grid energy consumers (Forde). The contribution of this collection is its explicit engagement with the multiple and sometimes conflicting ethical frameworks that animate these varied encounters with energy.

\footnotetext{
${ }^{5}$ The term complements the philosopher Michel Foucault's (1976) influential theorization of biopower, as a technique of power in which nation states regulate their subjects and control populations through managing bodies and life.
} 


\section{What kind of ethics?}

As noted by Nader, "experts often claim that energy solutions are purely technological” (2010:3). While this may indicate a commitment to late Modernity and its "almost unchallenged priority of scientific progress and technological innovation" (Barbour et al. 2010:33, see also Szeman and Boyer 2017:3), energy is never just technological in any strict or narrow sense of the word. As Goodman (1969) put forward in his provocation: "Whether or not it draws on new scientific research, technology is a branch of moral philosophy, not of science". ${ }^{6}$ This is because there is no neutral moral ground from which technology can be understood, implemented or pulled back. Any action is underpinned by the centrality of ethical practice and judgement, experience and reasoning, cultivation and questioning. With reference to energy research specifically, Sovacool thus observes that "it is a mistake to talk about building infrastructure, improving energy security, developing energy resources, forecasting future energy demands, or conducting research on new technologies without first asking what this energy is for, what values and moral frameworks ought to guide us, and who benefits" (Sovacool 2013:3).

In this Special Issue we want to take this further by recognizing how ethical considerations "recognition of persons, attributions of agency and responsibility, evaluations of states of affairs" (Laidlaw 2014:2) are not limited to researchers and other experts. We take seriously how ethical considerations are pervasive in human life among all actors. Some of these actors work in research laboratories to develop new biofuels (McLeod), while others draw on kinship values to determine how they will engage in off-grid household energy exchanges (Singh et al.). Again others engage in activism for more democratic forms of energy (Lennon), while still others visit a park that turns high-voltage transmission lines into potential aesthetic features of the landscape (Wuebben). Ethical considerations are ubiquitous and central to how humans act and interact (High 2016, Lambek 2010). This ethical constitution of human social life should be recognized in our energy research, as to do otherwise would be to ignore how people in their everyday lives make sense of and engage with energy.

In anthropology, a growing strand of scholarship has turned to ancient Greek and Roman ethics for conceptual inspiration. These ancient scholars offer a picture of morality closely bound up with everyday practices of self-cultivation, the perfection of specific technologies of moral development and an emphasis on developing a virtuous character as the basis for moral action in everyday political and social life. One of the attractions of the virtue ethics of Classical antiquity has been its possibility for engaging in an often critical dialogue with Kantian and utilitarian moral positions. But this attraction to moral philosophy is not without its reservations. Indeed, as discussed in the edited collection by Howell (2005), although this Classical strand of philosophy has a long intellectual tradition, it is not concerned with "locating the moral subject within social and cultural worlds" (ibid.:7). Given anthropology's ethnographic approach, moral projects are necessarily part of a wider historical, political, and socio-economic dynamic. To achieve a reinterpretation of virtue ethics that is sensitive to social life as lived, many anthropologists have turned for inspiration to Foucault's writings on moral subjectivation (e.g. Faubion 2010, Laidlaw 2002, Mahmood 2011). Applying an ethnographic gaze on ethics, anthropology thus examines "the human predicament of trying to live a life that one is somehow responsible for but is in many respects out of one's control" (Mattingly 2012: 179). That is, an

\footnotetext{
${ }^{6}$ Recognizing that this is a provocation that emerged in the late 1960s in the US, where fundamental shake-ups were vocalized, such statements can be seen as important precursors to later discussions, for example, by Bernard (1994) on the relationship between science and humanities.
} 
approach that is attentive to processes of ethical judgment grounded in both singular events and larger structures.

Given this conceptual orientation of anthropology, our calling for attention to energy ethics does not involve the scholar making a priori assumptions about what constitutes a good life, a good community, a moral person and the like. This is not an exercise in which scholars impose their own moral views on to those we study. Rather, it is call for us to be cognizant of the moral aspects of social life as it pertains to matters of energy. This means that this Special Issue is not advocating certain energy resources, energy practices, or energy politics above others. As Laidlaw remarks:

It is important not to confuse the claim that the ethical dimension is pervasive in human life with the quite different question of how often people meet or disappoint their own or anyone else's expectations or hopes. The claim on which the anthropology of ethics rests is not an evaluative claim that people are good: it is a descriptive claim that they are evaluative (2014:3).

Whilst recognizing the urgent politics surrounding energy, our mission is thus one of neither critique nor advocacy of the ethical positions taken by the people we study. This approach requires scholars to be self-reflexive about their own political commitments, to recognize when and how these influence our interpretation of ethnographic evidence, and to open up intellectual space for our interlocutors to enact and express commitments that differ from our own. This approach distinguishes our collection from much anthropological scholarship on energy, since energy is a subject matter that so often gets caught in scholars' implicit or explicit value judgements. Although only few scholars engage theoretically and empirically with questions of ethics, their publications are often informed by strong ethical persuasions. The focus on an impending energy transition in the context of climate change, for example, often asserts an ethical stance about particular energy futures that are deemed good or right. For example, the editors of the Special Issue on "Energy and Economy" of the journal Economic Anthropology argue that because "the postcarbon transition... is now inevitable", anthropologists must encourage people to "make room for the development of plausible postcarbon narratives" (Love and Isenhour 2016:8). Likewise, the editors of Cultures of Energy see anthropology's contribution to energy studies in terms of its help with "reducing global dependence on fossil fuels" in order to support more "sensible and sustainable" energy futures (2013:11). By casting particular sorts of energy sources and energy futures as good or desirable, little room is left for understanding how the people we study make sense of the world. We must be self-reflexive as we ask: Whose voices are being heard? What does an analytical framework allow us to see? And what does it hide? Embracing the ethnographic gaze with its many surprises and awkward scales, energy ethics is a term that itself entails an ethical project, valuing the intricacies of our imbrication with energy.

\section{What do these articles contribute to social science research on energy?}

The authors in this special collection all share an ethnographic approach to understanding energy. From blackouts in a Zambian copper mining town to the ideals of responsible research innovation that guide the work of British scientists producing biofuels, the articles illustrate the complex and contradictory ways in which people live with-and without - energy. The research spans multiple scales, from the off-grid "prosumers" in Wales who generate their own electricity (Ford), to people who live in the midst of vast energy infrastructures that concentrate the dilemmas of production, distribution, consumption, and waste in particular places, such as the 
Australian town contemplating a future with coal seam gas development (Grubert and Skinner), the Nebraskan park that domesticates the "wire evil" of high voltage transmission lines (Wuebben), and the New Mexican community that negotiates a nuclear waste site (Richter).

The collection as a whole underscores the multiple and conflicting understandings of energy that animate how people encounter energy in their everyday lives. Frigo provides a discussion of the multifaceted history of ideas that has contributed to the emergence of, what he calls, our "traditional energy paradigm". This paradigm influences our conceptualizations of energy, making us notice only certain measurable, quantifiable, and mechanistic properties of energy at the expense of many other diverse sets of properties. As such, Frigo shows how our paradigmatic conceptualization of energy is a particular cultural construct that is grounded in and shaped by centuries of increasingly homogenizing and colonizing discourses. Yet, for Frigo, alternative paradigms are possible and he invites us to think creatively about how we can better attend analytically to these. Lennon traces how distinctions in what energy is-including between the "BigE" and "little e" conceptions of fossil fuel industrial capitalism and decentralized, locally produced energies-come to matter in the intersection between the Black Lives Matter and energy justice movements in New York City. He provides a framework for not just democratizing, but decolonizing energy, disentangling energy systems from those that cause certain lives not to matter.

The collection also shows how people make ethical judgments about the role of energy in the societies which they imagine as 'good' or 'desirable'. Based on a qualitative methodology they call 'energy biographies', Groves et al. explore how members of different communities in Wales and London reflect on the role of energy use in creating lives which they themselves imagine to be 'good'. As the authors show, embodiment, attachment and life narratives affect implicitly and explicitly the ways in which people use and make sense of energy in their everyday lives. The result is a complex everyday energy ethics. Rather than being consistent about which energy practices contribute to good lives, the article shows how individuals can hold multiple and sometimes conflicting views simultaneously. Grubert and Skinner show that multiple and conflicting views of energy's contribution to 'the good' also animate community-level politics in their exploration of perceptions of proposed coal gas seam development in a town in New South Wales, Australia. Residents hold strong positions that coal seam gas would either endanger or facilitate a desirable future and quality of life. They trace this polarization to a long period of uncertainty about whether the development would go forward and a feeling among locals that they were not empowered to participate in those decisions. Wuebben's study of utility-owned arboretum in Nebraska invites us to consider how energy infrastructures can take on varying moral saliences, showing how high voltage transmission lines are sites of tension between landscape aesthetics and environmental ethics. Whereas transmission lines have historically been considered a blight or "wire evil," the arboretum is frequented by visitors who view it as a beautiful place, pointing to the possibility of a "power line poetics" that balances the aesthetics of electric infrastructures and the ethics of renewable energy development. Singh et al. critique dominant social science studies of the increasingly prevalent practice of energy trading, in which householders exchange locally provisioned (and usually renewable) energy with others. Whereas the existing literature assumes that people are motivated by "rational economic choices," their ethnographic intervention study in a rural village in India shows such market exchanges do not exhaust the spectrum of actual practices: people also engage in energy exchanges informed by the ideals of mutuality and obligation encompassed in kinship systems. The article by Chatti et al. also describes how energy practices, as well as academic and popular paradigms, are informed by multiple, and indeed conflicting, ethical judgments. Drawing on multidisciplinary debates surrounding bioenergy, discourse analysis and ethnographic research in the Indian Himalayas, the authors call for attention to so-called 'mundane bioenergy': The wood, dung, and 
crop residue that is used in cooking stoves across the world for people's subsistence needs. Although such bioenergy is often presented as an attractive 'green alternative', the authors argue that it often entails significant emissions affecting people's health and the climate, large-scale deforestation and other forms of environmental degradation. They thus encourage us to reflect on renewables as not necessarily a moral good for those who rely on them and the earth at large.

The articles also highlight the significance of government interests and public policy for shaping people's experiences of and ethical judgments about energy. Seeking to understand how residents of Carlsbad, New Mexico, came to accept nuclear waste, Richter examines the complex interplay of sociotechnical expertise, trust in governance, and visions of a desirable future present in their negotiations with the federal government. She brings together the analytical frames of energopower and technopolitics to show how the risks from radioactive waste were made understandable and manageable. Kesselring's examination of blackouts in new Zambian mining towns shows how electrical infrastructure is inherently political, structuring new social classes. The mines consume more than half the available electricity and maintain their supply even during shortfalls, despite the fact that there are daily blackouts and only one-fifth of households across Zambia are even connected to the national grid. In Forde's article, ethnographic research on off-grid ecovillages in Wales shows how villagers have to adapt their energy usage to temporal and seasonal energy fluctuations. This is partly due to the problem of how to store electricity, and partly due to the specific sociotechnical regimes implemented in each household. Forde argues that these encounters with energy give rise to a particular off-grid energy subjectivity. While the villagers see off-grid life as a moral reconfiguration of industrialized societies' relationship with energy, Ford shows how their energy subjectivity actually captures many of the elements of self-governance that is being promoted by the UK government. McCleod further shows the intersections between British government discourses and local energy practices in the context of a synthetic biology research laboratory that seeks to develop new sources of fuel from bacteria. While the government heralds the discoveries for their exciting promise, the scientists themselves feel less certain about the ethical projects entailed in their experiments. Some scientists voice their empathy for the anthropomorphized bacteria while others join in the triumphalist potentially new biological industrial revolution.

Together, the articles in this Special Issue ethnographically explore people's everyday engagements with energy, illuminating the multiple, varied and sometimes contradictory ethical stances that emerge as people live with and think about energy. Collectively they urge us to rethink the normative ethical frameworks that animate much academic scholarship and public debates about energy. Energy ethics invites us to become more self-reflexive about the assumptions and commitments driving our scholarship and to take the ethical sensibilities of others seriously as we collectively consider energy's role in the kinds of "good societies" we desire.

\section{Bibliography}

Agar, Michael (1986) Speaking of Ethnography. London: Sage.

Appadurai, Arjun (1990) Disjuncture and difference in the global culture economy. Theory, Culture, and Society 7: 295-310.

Appel, Hannah (2012) “Offshore Work: Oil, Modularity, and the How of Capitalism in Equatorial Guinea." American Ethnologist 39 (4): 692- 709.

Appel, Hannah, Arthur Mason, and Michael Watts, eds. (2015) Subterranean Estates: Life Worlds of Oil and Gas. 1 edition. Ithaca London: Cornell University Press. 
Apter, Andrew Herman (2005) The Pan-African Nation Oil and the Spectacle of Culture in Nigeria. Chicago: University of Chicago Press.

Barbour, Ian, et al. (2010) "Energy and the Rise of American Industrial Society." In The Energy Reader, pp. 32-44.

Behrends, Andrea, Stephen P. Reyna, and Gunther Schlee (2011) Crude Domination: An Anthropology of Oil. New York: Berghan Books.

Bernard, H. Russell (1994) "Methods Belong to All of Us”. In Assessing Anthropology, Robert Borofsky, ed., New York: McGraw-Hill. Pp. 168-179.

Bernard, H. Russell (2011) Research Methods in Anthropology: Qualitative and Quantitative Approaches. New York: Rowman Altamira Press.

Boyer, Dominic (2014) “Energopower: An Introduction.” Anthropological Quarterly 87 (2): 309-33.

—. 2015. “Anthropology Electric.” Cultural Anthropology 30 (4): 531- 39.

Brooks, Andrew. 2012. "Radiating Knowledge: The Public Anthropology of Nuclear Energy.” American Anthropologist 114 (1): 137- 40.

Comaroff, J ean and J ohn Comaroff (2003) "Ethnography on an Awkward Scale: Postcolonial Anthropology and the Violence of Abstraction”. Ethnography 4.2:147-179.

Coronil, Fernando (1997) The Magical State: Nature, Money, and Modernity in Venezuela. Chicago: University of Chicago Press.

Denzin, Norman K. (1997) Interpretive Ethnography: Ethnographic Practices for the 21st Century. London: Sage.

Ezzy, Douglas (2013) Qualitative Analysis: Practice and Innovation. London: Routledge.

Faubion, J ames D. (2011) An Anthropology of Ethics. Cambridge: Cambridge University Press.

Foucault, Michel (1978) The History of Sexuality, Vol. 1. New York: Vintage.

Fuller, S., McCauley, D. (2016) Framing energy justice: perspectives from activism and advocacy. Energy Research \& Social Science 11, 1- 8.

Gardiner, Stephen M. and David A. Weisbach (2016) Debating Climate Ethics. Oxford: Oxford University Press.

Geertz, Clifford (2000) 'The World in Pieces: Culture and Politics at the End of the Century". In Available Light: Anthropological Reflections on Philosophical Topics, pp. 218-263.

Gobo, Giampietro (2008) Doing Ethnography. London: Sage.

Goodman, Paul (1969) “Can Technology be Humane?” The New York Review of Books 13.20: 199-215.

Gusterson, Hugh (1998) Nuclear Rites: A Weapons Laboratory at the End of the Cold War. University of California Press.

Hammersley, Martyn, and Paul Atkinson (2007) Ethnography: Principles in Practice. London: Routledge.

Heffron, R.J ., McCauley, D. (2017) The concept of energy justice across the disciplines. Energy Policy 105, 658- 667.

High, Mette M. (2016) "A Question of Ethics: The Creative Orthodoxy of Buddhist Monks in the Mongolian Gold Rush”. Ethnos doi.org/ 10.1080/00141844.2016.1140215 
Howe, Cymene, and Dominic Boyer (2016) "Aeolian Extractivism and Community Wind in Southern Mexico." Public Culture 28 (2 79): 215- 35.

Howe, Cymene (2014) "Anthropocenic Ecoauthority: The Winds of Oaxaca." Anthropological Quarterly 87 (2): 381- 404.

Howell, Signe, ed. (2005) The Ethnography of Moralities. London: Routledge.

J enkins, K., McCauley, D., Heffron, R., Stephan, H., Rehner, R. (2016) Energy justice: A conceptual review. Energy Research \& Social Science 11, 174- 182.

J orgensen, J oseph G., Richard O. Clemmer, Ronald L. Little, Nancy J . Owens, and Lynn A. Robbins, eds. (1978) Native Americans and Energy Development. Cambridge: Anthropology Resource Center.

Kruse, J ohn, J udith Kleinfeld, and Robert Travis (1982) “Energy Development on Alaska's North Slope: Effects on the Inupiat Population." Human Organization 41(2):95, 97-106.

Laidlaw, J ames (2002) "For an Anthropology of Ethics and Freedom". J ournal of the Royal Anthropological Institute 8.2: 311-332.

Laidlaw, J ames (2013) The Subject of Virtue: An Anthropology of Ethics and Freedom. Cambridge: Cambridge University Press.

Lambek, Michael, ed. (2010) Ordinary Ethics: Anthropology, Language, and Action. New York: Fordham University Press.

Love, Thomas, and Cindy Isenhour (2016). "Energy and Economy: Recognizing High-Energy Modernity as a Historical Period". Economic Anthropology 3.1: 6-16.

Mahmood, Saba (2011) Politics of Piety: The Islamic Revival and the Feminist Subject. Princeton: Princeton University Press.

Masco, J oseph (2008) "'Survival is Your Business": Engineering Ruins and Affect in Nuclear America." Cultural Anthropology 23 (2): 361-98.

Mattingly, Cheryl (2012) "Two Virtue Ethics and the Anthropology of Morality". Anthropological Theory 12.2: 161-184.

McNeil, Bryan T. (2011) Combating Mountaintop Removal: New Directions in the Fight against Big Coal. Urbana: University of Illinois Press.

Mitcham, Carl, and J essica Smith Rolston (2013) "Energy Constraints." Science and Engineering Ethics 19 (2): 313- 19.

Nader, Laura, ed. (2010) The Energy Reader. Oxford: Wiley-Blackwell.

Nader, Laura (1980) Energy Choices in a Democratic Society. Washington: National Academy of Sciences.

-----. (1981) “Barriers to Thinking New About Energy.” Physics Today 34(9): 99-104.

O'Reilly, Karen (2012) Ethnographic Methods. London: Routledge.

Richardson, Tanya, and Gisa Weszkalnys (2014) "Introduction: Resource Materialities." Anthropological Quarterly 87 (1): 5- 30.

Rogers, Doug. (2015) The Depths of Russia: Oil, Power, and Culture after Socialism. 1 edition. Ithaca: Cornell University Press.

Rolston, J essica Smith (2014) Mining Coal and Undermining Gender: Rhythms of Work and Family in the American West. New Brunswick, NewJ ersey: Rutgers University Press. 
Rolston, J essica Smith (2013) "The Politics of Pits and the Materiality of Mine Labor: Making Natural Resources in the American West." American Anthropologist 115 (4): 582- 94.

Sawyer, Suzana (2004) Crude Chronicles: Indigenous Politics, Multinational Oil, and Neoliberalism in Ecuador. Durham: Duke University Press.

Sovacool, Benjamin (2013) Energy and Ethics: J ustice and the Global Energy Challenge. Basingstoke: Palgrave Macmillan.

Sovacool, Benjamin K., and Michael H. Dworkin (2014) Global Energy Justice: Problems, Principles, and Practices. Cambridge: Cambridge University Press.

Sovacool, B.K., Burke, M., Baker, L., Kotikalapudi, C.K., Wlokas, H. (2017) New frontiers and conceptual frameworks for energy justice. Energy Policy 105, 677- 691.

Sovacool, B.K., Heffron, R.J., McCauley, D., Goldthau, A. (2016) Energy decisions reframed as justice and ethical concerns. Nature Energy 1, 16024.

Strauss, Sarah, Stephanie Rupp, and Thomas Love, eds. (2013) Cultures of energy: power, practices, technologies. London: Routledge.

Szeman, Imre, and Dominic Boyer, eds. (2017) Energy Humanities: An Anthology. Baltimore: Johns Hopkins University Press.

Taylor, Stephanie, ed. (2001) Ethnographic Research: A Reader. London: Sage.

Weszkalnys, Gisa (2011) "Cursed Resources, or Articulations of Economic Theory in the Gulf of Guinea." Economy and Society 40 (3): 345- 72.

White, Leslie (1959) The Evolution of Culture. New York: McGraw Hill.

White, Leslie (1943) “Energy and the Evolution of Culture.” American Anthropologist 45(3): 335-356.

Willis, Paul and Mats Trondman (2000) “Manifesto for Ethnography”. Ethnography 1.1:5-16. 